3 Davis NM, Turco S. A study of particulate matter in IV infusion fluids-phase 2. Am $\mathcal{f}$ Hosp Pharm 1971;28:620-3.

4 Turco S, Davis NM. Particulate matter in intravenous infusion fluids-phase 3. Am $\mathcal{J}$ Hosp Pharm 1973;30:611-3.

5 Lewis GBH, Hecker JF. Infusion thrombophlebitis. Br f Anaesth 1985;57:220-33.

6 DeLuca PP, Rapp RP, Bivins B, McKean HE, Griffen WO. Filtration and infusion phlebitis: a double-blind prospective clinical study. Am f Hosp Pharm 1975;32:1001-7.

7 Bivins BA, Rapp RP, DeLuca PP, McKean H, Griffen WO Jr. Final in-line filtration: a means of decreasing the incidence of infusion phlebitis. Surgery 1979;85:388-94.

8 Rusho WJ, Bain JW. Effects of filtration on complications of post-operative intravenous therapy Am 7 Hosp Pharm 1979;36:1355-6.

9 Falchuk KH, Peterson L, McNeil BJ. Microparticulate-induced phlebitis: its prevention by in line filtration. N Engl f Med 1985;312:78-82.
10 Maddox RR, Rush DR, Rapp RP, Foster TS, Mazella V, McKean HE. Double-blind study to investigate methods to prevent cephalothin-induced phlebitis. Am f Hosp Pharm 1977;34: 29-34.

11 Dorris GG, Bivins BA, Rapp RP, Weiss DL, DeLuca PP, Ravin MB. Inflammatory potential of foreign particulates in parenteral drugs. Anesth Analg 1977;56:422-8.

12 Allcutt DA, Lort D, McCollum CN. Final inline filtration for intravenous infusions: a prospective hospital study. Brf Surg 1983;70:111-3.

13 Turco S, Davis NM. Clinical significance of particulate matter: a review of the literature. Hospital Pharmacy 1973;8:137-40.

4 Turco S, Davis NM. Glass particles in intravenous injections. N Engl f Med 1972;287:1204-5.

15 Shaw NJ, Lyall EGH. Hazards of glass ampoules. Br Med $\mathcal{F}$ 1985;291:1390.

6 Butler LD, Munson JM, DeLuca PP. Effect of inline filtration on the potency of low-dose drugs. Am f Hosp Pharm 1980;37:935-4

\title{
Drugs for poor sleepers?
}

Some people have always been poor sleepers, but nowadays there are more of them-because there are more elderly people. Patients have always wanted sleep inducing drugs, from Shakespeare's drowsy syrups to the benzodiazepines of today. If doctors accept recent criticisms of benzodiazepines are they justified in always withholding the drugs? I think not.

Patients who say that they have hardly slept a wink for a month or that they always take two hours to fall asleep are inaccurate. Monitoring with an electroencephalogram shows that such people are usually asleep within 20 minutes and sleep for six hours. Indeed, the impressive finding in the laboratory is the overlap in the amounts of sleep between those who complain and their matched controls. Yet, though the expert can say for how many minutes a patient slept, he can say almost nothing about the restorative intensity of the sleep. The patient maintains something is amiss; the expert cannot say he or she is wrong.

When matched groups are compared with the electroencephalograph people who complain of poor sleep do on average get half an hour less and do wake up more frequently than people who say that they sleep well. The poor sleepers are also hotter by night and by day, ${ }^{1.3}$ which would imply a higher rate of catabolism - and the greater need for restoration; yet their sleep is somewhat shorter and more broken. Evidently they are not mere complainers: they know something that we cannot fully measure. Also we do not know why people who say they habitually have under six hours a night when followed up for nine years should have had a mortality rate 1.3 times higher than expected. ${ }^{4}{ }^{5}$

The simple guides to better sleep are regularity in time of getting up in the morning, not smoking, minimising alcohol intake, taking regular exercise, forgiving your enemies, and deliberately planning happy thoughts at bedtime ${ }^{6}{ }^{7}$ Irregular times of evening food should be avoided-these disturb sleep-while the milk and cereal drink Horlicks at bedtime really does bring benefit. ${ }^{8}$ But none of these recipes rivals the potency of a modern hypnotic drug. 9

What about alternative techniques? Biofeedback training sessions use the tension in the muscles to produce a rate of clicks that informs the listener that she is or is not relaxing. Poor sleepers average high scores for tension and anxiety. Can training in relaxation improve their sleep? Nicassio et al trained poor sleepers in progressive relaxation or gave biofeedback or bogus biofeedback (the rate of clicks varying without relation to muscle tension). ${ }^{9}$ The genuine biofeedback and the progressive relaxation were no more effective than the bogus biofeedback. Hauri assessed 165 poor sleepers and thought that 54 might benefit from biofeedback. ${ }^{10}$ Yet after an average of 25 hours of training neither subjectively nor in the laboratory was there an overall advantage compared with one hour of simple counselling.

The subjective and laboratory evidence that modern hypnotics improve sleep is extensive. Statements that benzodiazepines do not long remain effective may be refuted ${ }^{11}{ }^{12}$ : tolerance certainly occurs, but it is only partial. The trouble is that with regular dosage the brain adapts its machinery to provide the partial tolerance. If the drug is then abruptly stopped a rebound occurs because of the changes in the brain, so sleep is temporarily worse than it would have been had the drug never been taken." Once these facts are understood the drugs can be used accordingly.

A recent leading article in the $B M \mathcal{F}$ asserted that benzodiazepines should not be prescribed at times of bereavement or divorce, ${ }^{13}$ but I think that it would be inhumane to pursue such a policy rigorously in the face of distress. Certainly patients should be told that hypnotics should be taken only in small dosages during short periods and preferably not every night. Time sorts out human troubles, the dosage may then be cut, and the drug stopped, rebound sleep troubles being balanced out by the amelioration of stress.

Many people keep a few sleeping pills at home for the odd occasion when experience suggests that the day's events will cause a troubled night. Today's hypnotics are safe and are as much modern facilities as telephones or videos. In Britain an effective hypnotic may now be purchased over the counter as Sominex (promethazine), and sufficient for several nights. I do not see why short acting benzodiazepine hypnotics should not be similarly available in Britain - where any adult is free to buy a bottle of vodka. Doctors need not always be intermediaries. If asked to prescribe they can take the opportunity to educate.

Professor of Psychiatry, University Department of Psychiatry,

IAN OSWALD Royal Edinburgh Hospital, Edinburgh EH10 5HF

1 Monroe LJ. Psychological and physiological differences between good and poor sleepers. $\mathcal{J}$ Abnorm Psychol 1967;72:255-64.

2 Mendelson WB, Garnett D, Gillin JC, Weingartner $\mathrm{H}$. The experience of insomnia and daytime and nighttime functioning. Psychiatry Res 1984;12:235-50.

3 Adam K. Are poor sleepers changed into good sleepers by hypnotic drugs? In: Hindmarch I, Ott H, Roth T, eds. Sleep, benzodiazepines and performance. Berlin: Springer-Verlag, 1984.

4 Kripke DF, Simons RN, Garfinkel L, Hammond EC. Short and long sleep and sleeping pills: is increased mortality associated? Arch Gen Psychiatry 1979;36:103-16.

5 Wingard DL, Berkman LF. Mortality risk associated with sleeping patterns among adults. Sleep 1983;6: 102-7.

6 Schwartz AK, Aaron NS. Sommniquest: the five types of sleeplessness and how to overcome them. London: Wildwood House, 1980

7 Oswald I, Adam K. Get a better night's sleep. London: Martin Dunitz, 1983.

8 Adam K. Dietary habits and sleep after bedtime food drinks. Sleep 1980;3:47-58.

9 Nicassio PM, Boylan MB, McCabe TG. Progressive relaxation, EMG feedback and biofeedback placebo in the treatment of sleep-onset insomnia. BrF Med Psychol 1982;55:159-66.

10 Hauri P. Treating psychophysiologic insomnia with biofeedback. Arch Gen Psychiatry 1981 38:752-8.

11 Adam K, Adamson L, Brezinova V, Hunter WM, Oswald I. Nitrazepam: lastingly effective but trouble on withdrawal. $\mathrm{Br} \mathrm{Med} \mathcal{F}$ 1976; ; $1558-60$.

12 Oswald I, French C, Adam K, Gilham J. Benzodiazepine hypnotics remain effective for 24 weeks. BrMed J 1982;284:860-3.

13 Higgit AC, Lader MH, Fonagy P. Clinical management of benzodiazepine dependence. BrMed $\mathcal{J}$ 1985;291:688-90. 